\title{
CORPOS POTENTES QUE VEEM, CORPOS FREAKS QUE SÃO VISTOS: ANÁLISES SOBRE UM CORPO MODIFICADO E NÃO-BINÁRIO
}

Márcio Alessandro Neman do Nascimento ${ }^{1}$ (D) https://orcid.org/0000-0002-2794-1594

Thi Angel ${ }^{2}$

https://orcid.org/0000-0002-2624-413X

Resumo: O presente artigo investe na análise de uma entrevista realizada no ano de 2014 (durante a pesquisa de doutoramento do entrevistador) e analisada e escrita conjuntamente com a entrevistade em 2019 (após seis anos). No processo polifônico foi salientada a experiência do próprio corpo de Thi Angel, performer art, professore de História de uma escola pública periférica de Osasco-SP, que nas duas últimas décadas pesquisa sobre modificação corporal (bodymodification) e os diferentes usos do corpo. Thi Angel aponta como a trajetória de suas modificações corporais caminhava junto com o ativismo pelos direitos sexuais e reprodutivos, direitos humanos e dos animais, sua conexão com o veganismo e a arte de performar. Durante a primeira entrevista, Thi Angel narra sua estilística de existência e as escritas e marcas construídas em seu corpo por meio da arte performática, como também traz as dificuldades de baixa visão devido à doença Ceratocone, desde os 14 anos, e a emergência de transplantes em ambos os olhos. Já em 2019, o reencontro para essa escrita polifônica relembra e anuncia as ocorrências vividas após 6 anos. O posicionamento cartográfico foi o suporte e conexão com o mundo para a realização das análises dos acontecimentos e das entrevistas que foram audiogravadas e transcritas na íntegra. Para a elaboração de tais análises recorremos às epistemes teórico-metodológicas da Filosofia da Diferença, da Teoria Queer, da Teoria Crip e dos Estudos de Gênero.

Palavras-chave: esquizoanálise; estudos de gênero; teoria queer.

1 Psicólogo. Professor adjunto do curso de Psicologia da Universidade Federal de Mato Grosso (UFMT/Câmpus Rondonópolis). Coordenador do Laboratório Esquizoanalista de Produção de Subjetividade e(m) Interseccionalidades (LEPSI). E-mail: marcioneman@gmail.com.

2 Professore em uma escola pública periférica de Osasco. Escritore, blogueire, trabalha com performance art e realiza ativismo em prol dos Direitos Humanos e dos Animais. Administradore do site:

http://www.frrrkguys.com.br/ 


\section{POTENT BODIES THAT SEE, FREAK BODIES THAT ARE SEEN: ANALYSIS ON A NON-BINARY AND MODIFIED BODY}

Abstract: The present article invests in the analysis of an interview conducted in the year 2014 (during the interviewer's doctoral research) and analyzed and written together with the interviewee in 2019 (after six years). In the polyphonic process the experience of Thi Angel's own body was highlighted, Thi Angel, performer art, history teacher of a peripheral public school in Osasco-SP, who in the last two decades researches about body modification (bodymodification) and the different uses of the body. Thi Angel points out how the trajectory of his body modifications went along with his activism for sexual and reproductive rights, human and animal rights, his connection with veganism and performance art. During the first interview, Thi Angel narrates her stylistic existence and the writings and marks built on her body through performance art, as well as brings the difficulties of low vision due to the disease Keratoconus, since the age of 14 , and the emergence of transplants in both eyes. Already in 2019, the reunion for this polyphonic writing recalls and announces the occurrences experienced after 6 years. The cartographic positioning was the support and connection with the world to carry out the analyses of the events and the interviews that were audiotaped and transcribed in full. For the elaboration of such analyses we resorted to the theoreticalmethodological epistemes of the Philosophy of Difference, Queer Theory, Crip Theory, and Gender Studies.

Keywords: schizoanalysis; gender studies; queer theory.

\section{CUERPOS PODEROSOS QUE VEN, CUERPOS VOLUBLES QUE SE VEN: ANÁLISIS DE UN CUERPO MODIFICADO Y NO BINARIO}

Resumen: El presente artículo invierte en el análisis de una entrevista realizada en 2014 (durante la investigación doctoral del entrevistador) y analizada y escrita junto con la entrevistade en 2019 (después de seis años). En el proceso polifónico, se destacó la experiencia del propio cuerpo de Thi Angel, artista performer, profesore de historia de una escuela pública periférica de Osasco-SP, que en las últimas dos décadas investiga sobre la modificación corporal (bodymodification) y los diferentes usos del cuerpo. Thi Angel señala cómo la trayectoria de sus modificaciones corporales fue acompañada de su activismo por los derechos sexuales y reproductivos, los derechos humanos y de los animales, su conexión con el veganismo y el arte de la performance. Durante la primera entrevista, Thi Angel narra su existencia estilística y las escrituras y marcas construidas en su cuerpo a través del arte de la performance, así como aporta las dificultades de la baja visión debido a la enfermedad del queratocono, desde los 14 años, y la aparición de trasplantes en ambos ojos. Ya en 2019, el reencuentro para esta escritura polifónica recuerda y anuncia las ocurrencias vividas después de 6 años. El posicionamiento cartográfico fue el soporte y la conexión con el mundo para llevar a cabo el análisis de los eventos y las entrevistas que fueron audiorregistradas y transcritas en su totalidad. Para la elaboración de dichos análisis, recurrimos a las epistemes teóricas y metodológicas de la Filosofía de la Diferencia, la Teoría Queer, la Teoría Crip y los Estudios de Género.

Palabras clave: esquizoanálisis; estudios de género; teoría queer. 


\section{Introdução}

O que acontece quando dois corpos se encontram para conversar? Gilles Deleuze e Claire Parnet (1998), em “Uma conversa, o que é, para que serve?", propõem que a entrevista seja pensada como uma conversa, como um encontro, um devir entrevistadoreentrevistade que aconteça sem um a priori, ou seja, sem ajustes classificatórios e lineares, afastando-se dos regimes de verdades. Nessa proposta de entrevista, não existem palavras certas ou erradas e ritmos e imagens coerentes e fixas, o que existe no itinerário rizomático é a evidência das rupturas e descontinuidades discursivas e a legitimação do que ocorre durante a expressão de percepções, sensações, afetos. Nesse sentido, não cabe impor objeções que interditem o discurso do outro, pois a entrevista acontece no "entre", na relação, na dupla captura no ato de quem fala e em conjunto com quem se fala, portanto, “[...] não há nada a compreender, nada a interpretar" (DELEUZE; PARNET, 1998, p. 12). Entretanto, após a entrevista, indaga-se: Quais registros esses corpos de mãos polifônicas podem analisar? É possível criar análises horizontalizadas e participantes?

Este artigo mescla dois momentos convergentes e complementares de entrevistas: a primeira realizada no ano de 2014, período em que Thi Angel foi entrevistade pelo primeiro autor, para a tese de doutoramento intitulada "Corpos (con)sentidos: cartografando processos de subjetivação de produto(re)s de corporalidades singulares" (2015), pesquisa acadêmica que, por meio do posicionamento cartográfico em intersecção com outros estudos sobre produção de subjetividades, entre eles, os estudos de gênero, filosofias pós-estruturalistas, entre outros, problematizava a insurgência dos processos de produções de singularidades corporais e de modos de subjetivação resistentes às éticas e estéticas das matrizes dominantes. $\mathrm{O}$ segundo momento aconteceu no final de 2019, disparado pela emergência da escrita deste artigo. No entanto, é fato que desde a primeira entrevista, a relação implicada da pesquisa se transformou em uma relação de amizade. A conexão polifônica, o devir Márcio-Thi Angel nunca diminuiu sua potência, marcadas por encontros em São Paulo, áudios e mensagens por Whatsapp, Facebook, e-mails, trocas de materiais, sempre no intuito de in/de/trans/formar observações e análises das rupturas e continuidade na (trans)contemporaneidade de expressões e de práticas sociais que podem (des)construir corporalidades e (re)montar estéticas inventivas e criadoras. Os recortes das entrevistas investidos para a análise 
dizem respeito à narrativa de Thi Angel sobre a estilística de sua existência plural e as escritas e marcas construídas em seu corpo por meio da arte performática e do body modification, como também traz as dificuldades de baixa visão devido à doença Ceratocone (desde os 14 anos, e a emergência de transplantes em ambos os olhos) e a insurgência da ideia de "interseccionalidade" para a academia, o movimento social e para a construção de análises mais equitativas.

\section{Um modo suspenso e transversal de se produzir conhecimento e outras conexões}

A partir do posicionamento teórico-metodológico adotado, problematizar e pesquisar corpos extrapola a elaboração de uma escrita apenas acadêmica, uma vez que a composição do que denominamos de "corpo" insurge dentre as intersecções sóciohistórico-políticas e culturais (AKOTIRENE, 2018; NOGUEIRA, 2017). Desse modo, as corporalidades acontecem nas construções discursivas, emergindo em modos de pensar, sentir, perceber, descrever, assim como também adentram os processos de estigmatização ou, como diria Gayatri Chakravorty Spivak (2012), corpos subalternos que precisam falar, denunciar, se defender, incomodar para sair do lugar de assujeitamento.

A partir da filosofia de Michel Foucault (2003a), evidenciamos que as práticas discursivas de sujeites anônimes não foram notadas em seus contextos existenciais, mas que, mesmo negadas, compõem a construção das realidades sócio-histórico-políticas e culturais. Em relação à importância de realizar análises discursivas sobre os acontecimentos a partir de outros prismas de existências de sujeites, Foucault (2003a) analisa:

Eu quis que se tratasse sempre de existências reais; que se pudessem dar-Ihes um lugar e uma data; que por trás desses nomes que não dizem mais nada, por trás dessas palavras rápidas e que bem podem ser, na maioria das vezes, falsas, mentirosas, injustas, exageradas, houvesse homens que viveram e estão mortos, sofrimentos, malvadezas, ciúmes, vociferações. Bani, portanto, tudo o que pudesse ser imaginação ou literatura: nenhum dos heróis negros que elas puderam inventar me pareceu tão intenso quanto esses remendões, esses soldados desertores, essas vendedoras de roupas de segunda mão, esses tabeliões, esses monges vagabundos, todos enraivecidos, escandalosos ou desprezíveis; e isso pelo único fato, sem dúvida, de que sabemos que eles existiram (FOUCAULT, 2003a, p. 206). 
Foucault propõe que fosse estabelecido o maior número de conexões possíveis com o campo psicossocial, vinculações que fossem "[...] uma peça na dramaturgia do real, que constituíssem o instrumento de uma vingança, a arma de um ódio, um episódio em uma batalha, a gesticulação de um desespero ou de um ciúme, uma súplica ou uma ordem" (FOUCAULT, 2003a, p. 206). Assim sendo, são essas existências breves, obscuras e silenciadas que, na insurgência potente de suas desgraças, paixões e ódios produzem pontos múltiplos de afetos e sensações que potencializam, mesmo que por instantes, regimes de visibilidades, resistências e afirmatividades; ou seja, atravessamentos resistentes de "encontro com o poder", assinalado como:

O que as arranca da noite em que elas teriam podido, e talvez sempre devido, permanecer é o encontro com o poder: sem esse choque, nenhuma palavra, sem dúvida, estaria mais ali para lembrar seu fugido trajeto. O poder que espreitava essas vidas, que as perseguiu, que prestou atenção, ainda que por algum instante, em suas queixas e em seu pequeno tumulto, e que as marcou com as garras, foi ele que suscitou as poucas palavras que disso nos restam; seja por se ter querido dirigir a ele para denunciar, queixar-se, solicitar, suplicar, seja por ele ter querido intervir e tenha, em poucas palavras, julgado e decidido. Todas essas vidas destinadas a passar por baixo de qualquer discurso e a desaparecer sem nunca terem sido faladas só puderam deixar rastros breves, incisivos, com freqüência enigmáticos - a partir do momento de seu contato instantâneo com o poder (FOUCAULT, 2003a, p. 207-208).

À vista disso, os diálogos-entrevistas mais equitativos analisam os afetos e transversalidades que emergem e constroem corporalidades, seja nos momentos possíveis de resistência, seja em momentos de produção de outros modos de pensar e praticar estilísticas de existências singulares e prazerosas. No entanto, Foucault (2006) também nos alerta sobre os agenciamentos que nos impulsionam para a ordem de um discurso majoritário e normativo, incita que (re)produzamos ordenamentos no campo discursivo.

Na obra "A ordem do discurso", Foucault (2006) analisa que o discurso poderia ser entendido como um conjunto de enunciados que se formulam por práticas sociais mediadas por regimes de verdades - regras, sentidos, signos, significados e representações - que são restritas e delimitadas no interior dos processos disciplinares e controladores dos discursos. Segundo o autor, para realizar análises por meio de acontecimentos discursivos, é preciso considerar o discurso como: 
[...] uma série de acontecimentos, de estabelecer e descrever as relações que esses acontecimentos - que podemos chamar de acontecimentos discursivos - mantêm com outros acontecimentos que pertencem ao sistema econômico, ou ao campo político, ou às instituições (FOUCAULT, 2003b, p. 256).

Esses processos podem produzir discursos fundamentais - que (re)produzem disciplinarmente práticas sociais ou atos de modo linear e contínuo -, como também produzem discursos criadores que (re)significam e subvertem as práticas instituídas em outros modos de ação. Esses últimos são discursos indisciplinados que almejam desconstruir as "verdades" ditas como "naturais", "normais" ou "certas", produzindo outros saberes que se confrontam com o instituído e o imposto.

Ao se localizar e questionar discursos que sejam legitimados hierarquicamente em relação a outros, onde situamos os gêneros e sexualidades (BUTLER, 2003), em um dado período histórico, colocamos em cheque o conjunto de estratégias e procedimentos tecnológicos que visam formular sujeitos normatizados e normalizados e que exclui e marginaliza tudo que acontece fora da rede inteligível do campo discursivo. Na mesma linha da análise foucaultiana sobre as práticas discursivas, Deleuze e Parnet (1998) problematizam a ideia de entrevista:

É difícil 'se explicar' - uma entrevista, um diálogo, uma conversa. [...]. As questões são fabricadas, como outra coisa qualquer. Se não deixam que você fabrique suas questões, com elementos vindos de toda parte, de qualquer lugar, se as colocam a você, não tem muito o que dizer. A arte de se construir um problema é muito importante: inventa-se um problema, uma posição de problema, antes de se encontrar uma solução. Nada disso acontece em uma entrevista, em uma conversa, em uma discussão. [...]. O objetivo não é responder a questões, é sair delas. [...]. Mas durante esse tempo, enquanto se gira em torno de tais questões, há devires que operam em silêncio, que são quase imperceptíveis (DELEUZE; PARNET, 1998, p. 9-10).

Da mesma forma que Foucault (2006), os autores supracitados analisam que haja um enrijecimento nas práticas discursivas que enfatizam significações dominantes sobre o passado e o futuro, em demasia sobre a história, o pessoal ou a descrição universal dos acontecimentos. Então, como escapar a essas formulações instituídas sobre como "dizer" 
sobre os acontecimentos? Como produzir discursos em que apareçam as sensações, percepções e afetos sobre os acontecimentos?

Primeiramente, Deleuze e Parnet (1998) realçam a possibilidade em problematizar entrevistas como traçados de devires, portanto, processos discursivos que não passam por uma filosofia classificatória, por práticas imitadoras e ajustadas a regimes de "verdades". Ao se propor a entrevista como devir, ela não pode ser construída como fenômenos de assimilação, imitação e linearidade, mas discutida por meio de

[...] dupla captura, de evolução não paralela, núpcias entre dois reinos. As núpcias são sempre contra natureza. As núpcias são o contrário de um casal. Já não há máquinas binárias: questão-resposta, masculinofeminino, homem-animal etc. Uma entrevista poderia ser simplesmente o traçado de um devir. A vespa e a orquídea são o exemplo. A orquídea parece formar uma imagem da vespa, mas, na verdade, há um devirvespa da orquídea, um devir-orquídea da vespa, uma dupla captura pois 'o que' cada um se torna não muda menos do que 'aquele' que se torna (DELEUZE; PARNET, 1998, p. 10).

De acordo com Deleuze e Parnet (1998), uma entrevista pode ser encarada como um encontro em que ocorre uma dupla captura (entrevistadore-entrevistade). Segundo os autores, "encontrar" é:

[...] achar, é capturar, é roubar, mas não há método para achar, nada além de uma longa preparação. Roubar é o contrário de plagiar, de copiar, de imitar ou de fazer como. A captura é sempre uma duplacaptura, o roubo, um duplo-roubo, e é isso que não faz, não algo de mútuo, mas um bloco assimétrico, uma evolução a-paralela, núpcias, sempre 'fora' e 'entre'. Seria isso, pois, uma conversa (DELEUZE; PARNET, 1998, p. 15).

Primeiramente, pensar entrevistas, diálogos como devires implica em aceitar o percurso de desterritorialização de atos expressos por estilos singulares. Assim, não existem palavras, frases, modos de dizer, ritmos, imagens, histórias, princípios ou consequências na dinâmica das conversações enquanto discursos formulados por certezas e fixidez. Todas as palavras podem ser criadas ou substituídas para expressar um estilo de como falar sobre as percepções, sensações, afetos. Nesse sentido, não caberia, no processo de entrevistar, impor objeções ou colocar questões que interditam o discurso do outro, pois a entrevista só pode ser analisada no ato de quem fala e em conjunto com 
quem se fala, portanto, "[...] não há nada a compreender, nada a interpretar" (DELEUZE; PARNET, 1998, p. 12).

Em segundo, outra pista interessante sobre o pensar no processo de entrevistar seria dar passagem aos traçados de linhas de fuga, ou seja, permitir que a multiplicidade de devires minoritários da língua aconteça na entrevista, isto é, "[...] devemos ser bilíngues mesmo em uma única língua, devemos ter uma língua menor no interior de nossa língua, devemos fazer de nossa própria língua um uso menor" (DELEUZE; PARNET, 1998, p. 12). O "multilinguismo" dessa proposta não se trata de possuir vários sistemas de "línguas" homogêneas em si mesmas, mas, sobretudo, subverter e inovar a ordem - por meio de linhas de fugas que difundem variações e heterogeneidades - dos sistemas lineares, homogêneos e sedimentados. Seria preciso ser um estrangeiro nômade em sua própria língua (BRAIDOTTI, 2000).

Uma terceira pista para pensar as entrevistas seria a problematização de que as pessoas são compostas por uma multiplicidade de linhas diversas e "elas não sabem, necessariamente, sobre qual linha delas mesmas elas estão, nem onde fazer passar a linha que estão traçando: em suma, há toda uma geografia nas pessoas, com linhas duras, linhas flexíveis, linhas de fuga etc" (DELEUZE; PARNET, 1998, p. 18). Nesse sentido, os discursos não seriam sempre da ordem normativa ou das linhas duras, sendo, portanto, necessário mapear o deserto que compõe as pessoas e compreender como esse território existencial foi atravessado e mobilizado por devires, movimentos, sons, entre outros afetos e sensações. Para os autores, nós “[...] somos desertos, mas povoados de tribos, de faunas e floras [...]. O deserto, a experimentação sobre si mesmo é nossa única identidade, nossa única chance para todas as combinações que nos habitam" (DELEUZE; PARNET, 1998, p. 19).

Seguindo uma perspectiva cartográfica, Tedesco, Sade e Caliman (2013) consideram que a entrevista deve ser analisada como um composto processual de experiências compartilhadas, estabelecida entre entrevistadore e entrevistade por meio da linguagem, dos afetos e sensações. No processo de entrevista, o(a) pesquisador(a) deve acompanhar os movimentos e ocasiões de rupturas e mudanças que ocorrem nas práticas discursivas. Quais processos e produções de (des/re) territorializações acontecem? Quais atravessamentos afetam e tornam discursos contínuos em disruptos? 
Quais palavras mobilizam e comovem? Quais sensações e imagens se tornam audíveis durante os processos da entrevista?

\section{Conversas (im)pertinentes: entre o céu e a terra... faíscas reluzentes}

A "confusão" iniciou-se já no começo da primeira entrevista. A questão ética do sigilo determinada pelo Comitê de Ética, de pesquisa com humanos, foi uma problemática a se tratar com Thi Angel, que me revelou se sentir incomodade em ter que utilizar um nome fictício para a entrevista. Segundo Thi Angel, como performer art se sentia constrangide em dizer sobre sua vida sem ter a autoria de suas experiências e práticas discursivas revelada, me indagando: "Bom, acho estranho não colocar o nome. Pois pensa comigo... vai que daqui 20 anos alguém quer saber quem falou ou pensava isso e daí não vai ter o nome da pessoa que pensava daquele jeito. Eu achava importante deixar o nome. [...] É que é a gente que fala e não tem nome (risos)".

Nas negociações para a primeira entrevista permaneceu o nome fictício escolhido para a pesquisa ${ }^{3}$ de "T3 ou F5". Em relação à segunda entrevista, como se tratava de uma parceria, uma co-autoria, Thi Angel assumiu sua autoria sobre suas difrações de maneira não anônima, nos moldes de uma entrevista pública.

No período da primeira entrevista, Thi Angel dizia temporariamente se identificar como homossexual, residia com a família, era ateu e se considerava colorido, uma vez que visivelmente apresenta grande parte do corpo modificada, principalmente no que tange às inúmeras tatuagens em todas as partes da extensão da pele. Na época namorava, já era formado pelo curso de História, trabalhava na área de performances artísticas e gerenciava o próprio site relacionado às estéticas e modificações corporais. Desde a primeira entrevista, afirmava utilizar roupas unissex, despojadas e com referências às culturas undergrounds da Contracultura para compor o visual casual. Oriundo de uma família evangélica (Congregação Cristã do Brasil), teve que produzir, desde a infância,

\footnotetext{
${ }^{3} \mathrm{Na}$ primeira entrevista, por se tratar de uma condição para a aprovação do projeto de pesquisa, foram respeitados os procedimentos éticos para pesquisas acadêmicas. Ainda, foram considerados os incisos constantes nas resoluções do Conselho Nacional de Saúde em que constava a autorização do registro das informações (áudio-gravadas e transcritas) e divulgações das entrevistas mediante o comprometimento do entrevistador em realizar pesquisa dentro dos moldes éticos e de manter o anonimato do colaborador, assim como constava o contato do pesquisador, da instituição de origem e do Comitê de Ética acionado.
} 
modos de resistência às normativas relativas ao seu estilo de vida, sua relação com as crenças, modos de vivenciar a sexualidade e experienciar o seu próprio corpo:

Eu não ficava nem sem camisa, sabe. Eu fazia natação e não tomava banho com os outros meninos porque eu tinha vergonha de ficar pelado. E também tinha a coisa de ser gay também. Então como ia ser? Eu voltava molhado embora, eu era besta e tal. Daí eu fui perder um pouco da vergonha em ter problemas com o corpo foi quando eu comecei a fazer a modificação corporal. As primeiras tatuagens foram me liberando o corpo aos poucos. Eu tatuava as pernas, e daí veio a bermuda que eu passei a usar. Eu tatuei os braços, e daí veio as regatas que também comecei a usar (T3 ou F5, 2013).

Acordamos que, para o reencontro para a segunda entrevista, leríamos a primeira entrevista constante nos anexos de Nascimento (2015), destacaríamos o que considerássemos pertinente para as difrações entre o "passado, presente e futuro" e decidiríamos em conjunto quais pontos em comum elencaríamos para problematizar. Assim sendo:

Márcio: Você havia dito na outra vez que se autodenominava homossexual, mas que já circulava a ideia da transexualidade, muito por conta do projeto T. Angel. Disse que não se via como uma mulher de seios e vagina, que gostava da ideia de pinto e seios; um corpo masculino e uma identidade de gênero feminino, com a sensibilidade feminina que encontra em suas amigas. Que queria ser um gênero neutro, pois tão pouco se via como um homem, mas gostava da força do seu corpo para poder performar. Era confuso para você a ideia de gênero feminino sem fazer a cirurgia. Também disse que estava namorando, em um relacionamento homossexual, pois seu namorado era gay. $O$ que mudou de lá para cá?

Thi Angel: Uau! Daquela entrevista para cá muita coisa mudou. Mudou pencas! O namoro acabou e desde então nunca mais quis namorar. Não foi trauma e nem nada, mas dentro de tudo que acredito e vivo não sinto que um relacionamento caiba. Obviamente que sei que essas coisas, muitas vezes, fogem do nosso controle, mas não é algo com que gasto minha energia e desejo. Está fora da minha lista de prioridades. E bem, na realidade aquela entrevista me trouxe termos e conhecimentos que me eram distantes até então. Talvez por isso também tenha deixado de namorar, estou em um processo de encontro comigo mesma. Sei lá... Lembro que enquanto a gente conversava daquela vez surgiu a palavra queer. Você disse que eu era queer e eu não fazia ideia do que isso queria dizer. Fui pesquisar sobre e acabei me encontrando demais, doutor. Na verdade, eu sinto que ainda estou me encontrando e tem sido um processo bonito e intenso. Hoje eu me entendo enquanto uma pessoa trans não binária e pansexual, embora a minha atividade sexual siga sendo baixa. Tenho abraçado o feminino que habita em mim e que por tanto tempo escondi e neguei. Tenho feito uma transição de gênero que atende as minhas expectativas 
e tempo. Sinto que todo dia é um passo a mais. Não é um processo de todo fácil, mas tem sido bom viver isso. Estou vivendo a melhor fase da minha vida. Nunca quis viver tanto como agora. Daquela vez que falamos eu estava feliz, mas não era como agora... Nunca é.

Márcio: $O$ que mudou em seu corpo, em relação ao body modification e à identidade de gênero?

Thi Angel: Bixa! Mudou muito. Além das coisas que eu escolho, tem as que eu não escolho, como por exemplo as mudanças que o avançar da idade tem trazido. Estou ficando uma senhorinha babadeira. Aloca! Eu fiz mais tatuagens, tenho tatuado partes de extrema visibilidade como rosto, mãos, pescoço e tem sido muito importante dentro do meu processo... Muito! Fiz mais implantes de silicone, no braço dessa vez. Devo ter feito mais um piercing ou outro. Fiz mais um transplante de córnea. Estou desde o ano passado passando pelo laser para retirar os pelos do meu corpo. Estou fazendo axilas, barriga e rosto. A minha barba morreu e eu tinha muita barba, cê lembra, bee? Odiava, sofria com ela. Fazia anos que eu queria tirar, mas não tinha dinheiro. Agora tenho salário (naquela época não tinha), parcelei em mil vezes no cartão e estou me realizando nesse sentido. Tem sido um processo extremamente doloroso e eu só não desisti pelo efeito positivo fantástico na minha disforia. A merda é que demorei demais pra começar e por conta da minha idade a barba começou a embranquecer e os malditos pelos não morrem. É algo que vou ter que lidar, mas sério, melhorou demais a minha relação com essa parte de mim. Parei de chorar e sangrar enquanto faço a barba. Pretendo iniciar a minha hormonioterapia em 2020. Fui ao endócrino e não foi muito legal. Ele me encaminhou ao psicólogo e psiquiatra e pediu pencas de exame, tô com tudo aqui parado. Fui no psiquiatra que me encaminhou ao Hospital do Servidor em São Paulo, ele disse que lá eles adorariam ter um caso inusitado como o meu (yuke?) para estudar. Liguei pra marcar a consulta e não tem agenda livre de psiquiatra no IAMSPE, ou seja, sem isso não consigo começar os hormônios. Entendo demais o motivo pelo qual as pessoas trans fazem automedicação. Entendo demais o motivo pelo qual a estimativa de vida das pessoas trans seja tão baixo. A negligência que paira sobre nossas vidas é violenta e nos assassina também. Preciso ter agora uma organização do meu horário na escola pra ir até o ambulatório que atende travestis e pessoas trans em São Paulo. Vou tentar por essa via já que pelo IAMSPE é impossível e particular eu não consigo pagar. Estou chegando nos 40, sabe? Queria agilizar esse processo pra mim. Vamos ver o que rola. A minha identidade de gênero é essa, não binária. A maioria das pessoas que me conhece me trata no neutro elou feminino e isso me traz um conforto maravilhoso. Há uma parte que me trata restritamente no masculino e embora na minha cabeça não faça sentido algum, não me chateio. Não é algo que eu quero brigar por enquanto, quero que seja um processo orgânico, como foi com as outras pessoas. Entendo que as pessoas ainda fazem uma leitura reducionista e simplista de mim enquanto homem, cis e gay e, por enquanto, tá tudo bem. Tudo bem ser lida como bixa. Embora eu não seja cis-homo, espero que um dia as pessoas entendam, escutando o que venho falando ao longo de todos esses últimos anos... Talvez desde que nasci, né querida?

Em análise conjunta, relembramos, a partir da narrativa de Thi Angel que as privatizações e interdições de sua corporalidade passou por diversos procedimentos de 
disciplinas e controles biopolíticos, sejam eles referenciados pelas instituições "família", "escola", "igreja" e "medicina" (FOUCAULT, 2003c). Ao longo da adolescência, a sua performance de gênero se afastava daquelas preconizadas pelo sistema sexo/gênero (BUTLER, 2003, 2004), desfazendo o arranjo linear homem/masculino ao rejeitar as performances impostas aos meninos do bairro e da comunidade escolar. O sofrimento psíquico crescente era intensificado pelas hostilizações expressas por parentes, religiosos e moradores da comunidade periférica em que habitava/habita no município de OsascoSP e também pelo medo de apanhar de punks e skinheads quando decidia sair de casa e "dar os seus rolês" pelas ruas de São Paulo.

A partir da narrativa de Thi Angel, nos atentamos aos estudos de Judith Butler (2003), que denuncia o modo de como o poder opera na produção de estruturas binárias por meio de uma matriz de inteligibilidade que, por sua vez, propõe estabilidades internas, linearidades e conformidades para explicar categorias fundacionais, onde localizamos as corporalidades, os desejos, as sexualidades, os prazeres, os gêneros, entre outras categorias que compõem os sujeites. Nessa lógica, Butler analisa que:

[...] a 'coerência' e a 'continuidade' da 'pessoa' não são características lógicas ou analíticas da condição de pessoa, mas, ao contrário, normas de inteligibilidade socialmente instituídas e mantidas. Em sendo a 'identidade' assegurada por conceitos estabilizadores de sexo, gênero e sexualidade, a própria noção de 'pessoa' se veria questionada pela emergência cultural daqueles seres cujo gênero é 'incoerente' ou 'descontínuo', os quais parecem ser pessoas, mas não se conformam às normas de gênero da inteligibilidade cultural pelas quais as pessoas são definidas (BUTLER, 2003, p.38).

Para Butler (2003, p. 39), resistir ou driblar a matriz de inteligibilidade e propor "impossibilidades lógicas", rupturas e descontinuidades requer investigar o (des)centramento nas "[...] apostas políticas, designando como origem e causa categorias de identidade que, na verdade, são efeitos de instituições, práticas e discursos cujos pontos de origem são múltiplos e difusos" (BUTLER, 2003, p. 9). Nessa discussão, Thi Angel, ao fugir e/ou se esquivar das institucionalizações das identidades rígidas, adentrou uma trama de relações de poderes que a diferenciava, a colocava à margem e em processos de estigmatização e de discriminação. Corroborando para essa discussão, Hall (2003, p. 110) analisa que as identidades funcionam, ao longo da história, como pontos 
estratégicos de identificação e pela capacidade de marcar como exterior, e assim, diferenciar como algo indesejável, uma vez que "[...] as identidades são construídas por meio da diferença e não fora dela [....]".

O "perceber-se" transexual e a experiência trans relatada por Thi Angel nos faz pensar no conjunto de resistências aos modelos coerentes e contínuos entre o sexo, gênero, prática sexual e desejo. Salientamos assim que as tecnologias de modificações corporais podem reificar o binário sexual, mas também podem funcionar como um potente dispositivo de problematizações da dicotomia corpo natural versus corpo social e a rigidez do sistema sexo-gênero. Analisamos que Thi Angel problematiza as questões de gênero quando desassocia o uso da body modification (uso de técnicas, rituais de dor) como uma condição destinada às construções apenas das masculinidades, e assim embaralha códigos instituídos ao gênero feminino e ao gênero masculino para constituir sua estética como, por exemplo, usar brincos, unhas pintadas, shorts extremamente curtos, camisetas curtas e com detalhes ditos como "femininos", entre outros.

No que tange aos processos de subjetivação singular, ou seja, o modo como Thi Angel vê o mundo, analisamos que há um misto de sentimentos e confusão, uma vez que o posicionamento trans e as modificações corporais (por meio das técnicas da body modification) aconteceram, mais fortemente, em concomitância. Os processos desejantes da transexualidade, os discursos e as representações imagéticas, assim como as práticas realizadas pelo body modification, se inserem nas perspectivas de suas experiências e experimentações.

A potência da (des)construção do estilo de vida de Thi Angel propõe a transposição da corporalidade, sexualidade, sensibilidades, sensações, afetos e modos de pensar e agir, isto é, novos processos desejantes e outras políticas existenciais. No entanto, para aqueles sujeitos da diferença, cuja polaridade identitária recai sobre a negatividade da estigmatização, inadequação social ou marginalização (manifesta ou silenciada), Butler (2003) retoma o conceito de abjeto. O posicionamento abjeto "[...] designa aquilo que foi expelido do corpo, descartado como excremento, tornado literalmente 'Outro'. Parece uma expulsão de elementos estranhos, mas é precisamente por meio dessa expulsão que o estranho se estabelece [...]" (BUTLER, 2003, p. 190-191).

A abjeção se fundamenta no repúdio e na patologização de um significante/sujeito (ou de um significante/classe-de-sujeitos) que deve ocupar uma zona inabitável e inóspita, 
ser encarado na condição marginal, na condição de inominável, inaceitável, intolerável, indesejável, abominável e de excremento e a ser destituído das fronteiras que qualificam/legitimam os sujeitos como seres humanos e sujeitos de direitos (BUTLER, 2008). Evidenciamos essa sensação quando Thi Angel é hostilizade por pessoas na rua e quando vai ao endócrino e este o direciona ao psicólogo e ao psiquiatra, além de verbalizar que aquele se tratava de um caso inusitado para ser estudado.

As identidades, sejam elas polarizadas normativamente ou no status de abjeto, são significações discursivas e de práticas sociais que situam os sujeitos (e seus discursos) em lugares que os permitem interpelar e acessar o mundo (falar/desejar/agir/circular/existir). Assim sendo, nesses processos se constroem sujeitos por meio de produção de subjetividades, que ora normatiza e ora singulariza as corporalidades e suas conexões com a vida. Portanto, as identidades podem ser encaradas como transitórias e temporárias às posições-de-sujeitos, articuladas nos "entres" fluxos de discursos.

Dentro das discussões sobre a abjeção, retomamos para a segunda entrevista um ponto delicado da vida de Thi Angel. A condição de sua baixa visão:

Márcio: O que mudou em relação a sua dificuldade visual? Em 2013 você iria operar os olhos. Estava com baixa visão por causa do ceratocone, e com muita dificuldade para enxergar, precisando de transplantes nas duas córneas. Estava com medo de ficar cego, pois a espera por transplantes era agoniante. Como está isso hoje?

Thi Angel: Quando a gente conversou da outra vez eu tinha operado só um olho, né? Pois bem, fiz o outro transplante em 2013. Fiz pelo SUS no Hospital São Paulo. Foi maravilhoso. Eles não queriam me operar porque me consideravam muita nova e a chance de rejeição ou de dar errado existia. Mas eu já não enxergava mais nada com aquele olho. Se desse errado eu seguiria não enxergando, mas havia a chance de voltar a ver e foi isso o que considerei. Felizmente deu tudo certo. A minha situação mais crítica com a visão foi antes do primeiro transplante. A queda foi muito rápida e até descobrir o diagnóstico demorou... Te contei que uma médica simplesmente disse que eu iria ficar cega? Simples assim. Foi meio foda ouvir isso aos 15 anos. Tipo, como assim, querida? Minha mãe ficou passada na época. Atualmente eu uso óculos porque me restou a miopia e o astigmatismo. $O$ ceratocone se foi. Consigo fazer tudo normalmente e até rolou tirar carta de motorista, só não consegui comprar o Angel Móvel ainda pra dar um close por aí. Achei que nunca fosse conseguir tirar carta. Sinto apenas que, assim como antes, em ambientes com pouca luz a minha visão cai consideravelmente. Mesmo de óculos eu sinto que preciso forçar mais. Mas é isso, a qualidade de vida que tenho agora é outra. Boto meus óculos de closeirinha e enxergo tudooooo, meu amor. 
De acordo com Anahi Guedes de Mello (2016), os estudos da Teoria Queer auxiliaram no apoio dos estudos sobre deficiência (Disability Studies), colaborando para a insurgência da Teoria Crip. A luta (trans)contemporânea contra a heteronormativividade e a heterossexualidade compulsória parecem apoiar a luta demandada contra a corponormatividade que elencam a uma matriz estética padrão em detrimento de uma ampla diversidade corporal.

A ideia central da Teoria Crip consiste na quebra do binário paradigmático capacidade/deficiência construída historicamente. Assim sendo, os estudos recentes sobre o capacitismo estudam os modos pelos quais as pessoas que apresentam algum tipo de deficiência são tratadas como “incapazes" (MELLO; NUERNBERG, 2012), passando por processos de estigmatização e discriminação, uma vez que a deficiência realiza intersecção com outros marcadores sociais, tais como: raça/etnia; orientação sexual; identidade de gênero; geracionalidade; classe social e econômica; oriundos de territorialidades específicas, entre outros. Esses corpos com deficiências, que são marginalizados e excluídos das diversas esferas da vida social (empregabilidade, conjugalidade etc) são postos no campo da abjeção, que pode ser compreendida como:

\begin{abstract}
A abjeção ou repulsa que o corpo deficiente provoca nos 'normais' afeta a relação com o outro e com o próprio corpo naquele que se sente diferente, [...] que se soma à exigência de encaixar o outro dentro de padrões hegemônicos antropométricos, fisiométricos e psicométricos, sendo ele exterminado ou segregado, apartado do convívio com os 'perfeitos, belos e saudáveis' (MELLO; NUERNBERG, 2012, p. 644).
\end{abstract}

A partir da narrativa de Thi Angel, na primeira entrevista, em 2013, lembramos o medo que pairava em relação à perda total da visão. A baixa visão ocasionada pelo ceratocone a impedia de tirar carteira de motorista, pois ela apresentava dificuldade para ver nitidamente e percepção alterada, condições que dificultavam a empregabilidade e levava ao estigma de usuário de "fundo de garrafa". O ceratocone dificultava que Thi Angel desenvolvesse seus cursos de artes performáticas (prática de suspensão corporal), uma vez que a baixa visão a colocava em risco em performances em que eram necessárias perfurações corporais.

Atualmente, Thi Angel fez a cirurgia nos dois olhos, entretanto, apresenta miopia e astigmatismo e por isso mantém o uso de óculos de alto grau, pois ainda apresenta um 
pouco de dificuldade em enxergar. O histórico de dificuldades pelo qual passou fez com que, atualmente, em seu ativismo, também seja voltada para a defesa da amplitude e visibilidade da diversidade corporal, ou seja, as diversas habilidades desenvolvidas por corpos que apresentam alguma deficiência.

As lutas travadas pelo ativismo de Thi Angel se apresentam plurais, pois todos os movimentos sociais e posicionamentos que potencializam a diversidade da vida adentram suas práticas sociais. Assim sendo, continuamos a conversar:

Márcio: $O$ que você pensa sobre como os ativismos produzidos dentro da comunidade body modification se coadunam com a luta das expressões plurais das sexualidades e de gêneros e das deficiências em pessoas?

Thi Angel: A interseccionalidade, né more? Pode faltar não. Eis mais uma palavra que eu aprendi de uma forma bonita. Certa vez, bons anos atrás, uma pessoa escreveu que adorava o frrkguys, o site que administro, porque havia um trabalho interseccional e eu não fazia ideia do que isso queria dizer, mas aparentemente eu estava fazendo (risos). Acredito que a proposição do movimento freak traz essa potência política, consciente $e$ crítica. Mas é algo bem pequeno quando comparamos com todo o resto. É uma célula de resistência contra a higienização que a comunidade da modificação corporal vem passando. Se a base da cultura da comunidade body mods era o underground, a contracultura, hoje já não é mais assim... Tem uma geração que não teve e não conhece essa experiência (e talvez nunca nem saiba que existiu). Tem uma geração que está mais afinada com o discurso dominante do que qualquer outra coisa. Hoje temos pessoas abertamente fascistas dentro da comunidade body mods, no passado a gente tinha também, mas era algo mais velado, hoje a galera coloca luminoso na porta do estúdio. São outros tempos... No mais, a gente precisa pensar - como parte de um processo de autocrítica - nos pactos que fizemos para que nossas práticas se tornassem lucrativas, atendendo todas as demandas do capitalismo. Exploração, acumulação, etc... Esse é um ponto que a gente precisa parar pra refletir pra saber onde estamos pisando e onde queremos pisar. Por isso a importância pra mim de se manifestar enquanto freak, dentro do que está postulado no Manifesto Freak ${ }^{4}$. Assim como a ideia de queer arrasta todo um

\footnotetext{
${ }^{4}$ Quando falamos sobre o movimento freak, não estamos falando exatamente da freak scene norteamericana das décadas de 60 e 70 . Pelo termo freak scene, se entende um movimento radicalmente politizado, que aconteceu na segunda metade do século XX e que se tornou compreendido como algo entre o pós-hippie e o pré-punk. Embora com tantas relações, proximidades e continuidades, quando falamos sobre movimento freak, estamos falando da seguinte configuração: Movimento relacionado diretamente com pessoas que por iniciativa pessoal alteram seus corpos com técnicas que escapam do conceito normativo estético, que é político. Para ilustrar a ideia temos a Erik Sprague conhecido como The Lizardman, que usando diferentes técnicas de modificações corporais reproduziu em si a imagem de um réptil. Em seu peito está gravado em tatuagem a palavra freak. Como The Lizardman, inúmeras pessoas da comunidade da modificação corporal carregam a palavra estampada de modo indelével no corpo. É um movimento consciente que toda estética é política e toda política é também estética. Nesse sentido, quando falamos de movimento freak, estamos falando de pessoas que além de preocupadas com a defesa da autonomia sobre o próprio corpo e o direito de uso do próprio corpo, estão atentas - em diferentes níveis - à intersecção entre gênero, sexualidade, classe social e econômica, raça, espécie, território,
} 
posicionamento político. Se hoje temos o luxo, o shopping, a academia, no passado era o lixo, a rua e a vivência como construção do conhecimento. Não é cair numa reflexão maniqueísta, mas olhar com atenção para as transformações. Acredito que dentro do movimento freak - que tem se construído dentro dessa configuração consciente $e$ declaradamente política - exista a possibilidade de fazer essa intersecção com a luta das dissidências sexuais e de gênero e também das pessoas com deficiência. Não posso dizer o mesmo por toda a comunidade body mods. Os interesses são outros.

A partir desse trecho da entrevista, analisamos que Thi Angel utiliza seu corpo como um dispositivo político e emancipatório quando utiliza a body art (por meio das suas performances artísticas) para quebrar as regras da inteligibilidade cultural em relação aos gêneros, denunciando a homofobia, o machismo, o racismo, o elitismo e o "ódio ao corpo e ao prazer". O foco de sua performance art, como por exemplo, nas edições da Virada Cultural de São Paulo, geralmente recorre às inscrições artísticas da body art como problematizadores para pensar o controle social sobre os corpos, mas também apresenta a plasticidade, as possibilidades e os usos corporais inteligíveis. Dentre as lutas ativistas de Thi Angel, que buscam a equidade de direitos sociais e lutam em defesa da pluralidade, podemos citar as: dos veganos, dos animais, dos LGBT's, dos negros, dos indígenas, do meio ambiente, dos discursos contra a violência contra as mulheres, crianças e idosos e também contra as intolerâncias religiosas.

A body art se refere à utilização dos corpos como dispositivos políticos e reivindicatórios contra os cerceamentos de livres expressões e das cristalizações identitárias dos corpos. Nela, a multiplicidade e plasticidade estética e de sensações e sentimentos são experienciadas e ativas nos e pelos instrumentos contextualizados nas artes performáticas - os corpos (LE BRETON, 2003; NASCIMENTO, 2015). Embora as performances na body art oscilem nas características singulares de seus artistas, geralmente são apresentadas enquetes com componentes radicais e agressivos contra o próprio corpo, visando produzir questionamentos contundentes que giram em torno da “[...] identidade sexual, os limites corporais, a resistência física, as relações homemmulher, a sexualidade, o pudor, a dor, a morte, a relação com os objetos [...]" (LE BRETON,

geração e deficiência, como postula o Manifesto Freak (ANGEL, 2016). É importante salientar que a palavra freak (aberração) foi usada no passado no sentido pejorativo e da desumanização. No entanto, a palavra foi apropriada pelo grupo, ressignificada e hoje representa uma identidade, aproximando-se, assim, das proposições da teoria queer e teoria crip. 
2003, p. 44). Ou seja, na body art é anunciada as conexões entre processos subjetivos dos(as) atores/atrizes e as linguagens das artes (técnicas e filosóficas) que insurgem em performances contestatórias que evocam o não-convencional, o grotesco, o esdrúxulo, o absurdo, o sem nexo e o abjeto (temos como exemplo os freakshows).

O projeto corporal de Thi Angel não se traduz apenas em modificações de seu corpo; é muito mais do que isso. Ao se compor singularmente, Thi Angel adentra os percursos das experimentações e das sensações, que, por sua vez, compõem os processos de produção de subjetividades singulares. O projeto que o acompanha há uma década denominado de "Projeto T. Angel" provoca a experiência do sensível ao buscar as desestabilizações de territórios sedimentados que interditavam as (re)configurações de suas formas, de seus posicionamentos, de seus afetos e de seus desejos.

Scott (1999) trata as "experiências" como atributos linguísticos que acontecem tanto nos planos coletivos quanto nos planos individuais, sendo dotadas de processos de significações mutáveis. Nesse sentido, os sujeitos não podem ser encarados como elementos que possuem as experiências, mas que, de fato, são constituídos por elas. Ou seja, não existe um "ser" sujeite, mas um "fazer" sujeite dado por recorrentes práticas e estados vividos no campo social. Tampouco podemos pensar as experiências com propriedades que existem a priori nos corpos viventes. Elas acontecem nas relações, nos atravessamentos, nos encontros entre os sujeitos e o "mundo exterior" (complexo de inscrições sociais) que resultam em um conjunto de sensações e significações, subsequentemente, produzindo sujeites.

Thi Angel ao romper com as referências instituídas e padrões dominantes de como "se comportar" nos faz lembrar que o corpo precisa, em sua emergência, vibrar a partir de uma multiplicidade de experiências, de sensações e conexões com o campo social. Todavia, Scott (1999) indica que não há experiências afastadas de contextos discursivos, uma vez que elas compõem uma historicidade. Isto é, mesmo que as experiências sejam estados vividos autênticos e imediatos (percepções, afetos e sensações), elas trazem histórias e "verdades" das posições dos sujeites. A experiência, em sua potência transformadora e viva, possibilita aos sujeites alcançar e compor "outras" condições de existências e nos parece que Thi Angel esteja promovendo isso de modo coletivo, ao compartilhar a sua arte. 


\section{Concluindo uma entrevista: quando a conversa de dois revela uma multidão}

De maneira conjunta, analisamos que a sociedade ocidental engendrou dispositivos disciplinares e de controle que produziram modos de subjetivar, de fazer gêneros, sexualidades, (d)eficiências, estilos de vida, entre outros e, subsequentemente, modos de produzir prazer e estéticas corporais em uma lógica do poder-saber-prazer. Mediante a isso, mesmo com os avanços dos Direitos Humanos e propagação das vidas plurais, enfrentar os binarismos que sustentam o machismo, a misoginia, o racismo, a LGBTfobia, o capacitismo, entre outros, não parece tarefa fácil.

A árdua luta acontece por meio de enfrentamentos de relações assimétricas e de assujeitamentos que se construíram sócio-histórico-política e culturalmente durante séculos. No entanto, também é fato que, ao longo da história, muitas transformações no campo psicossocial ocorreram devido a pessoas raras, ativistas, coletivos e movimentos sociais que produzem resistência e singularidades e possibilitam a construção de paisagens com uma diversidade de protagonistas de narrativas potentes, abrindo caminho para aqueles(as) que virão.

Os modos de combater os processos de estigmatização, marginalização, exclusão e extermínio não caminham progressivamente de maneira linear e unilateral, uma vez que os acontecimentos sociais apresentam uma multiplicidade de conexões que produzem continuidades e rupturas. Assim, é preciso coragem, atenção, sensibilidade, práticas e discursos para enfrentar o "cio da cadela" do fascismo que sempre anda à espreita das vidas raras.

Todavia, indagamos: Como proceder diante de todos os retrocessos presentes? Assim como na história, não existe um a priori, no entanto, seguimos uma pista problematizada por Foucault (2005, p. 91), que seria: “[...] lá onde há poder, há resistência [...].", ou seja, é necessário criar mecanismos e estratégicas de combate à normatização das estilísticas das existências, possibilitando a expansão dos fluxos de desejos e da ética dos gêneros/sexualidades e da diversidade corporal.

A figura de T. Angel, anjo caída, sem sexo e gênero em trânsito, na nossa observação, propõe resistência potente e criativa. Pensar as experiências contextualizadas e localizadas em dados momentos sócio-histórico-políticos e culturais evidencia as tensões e embates no campo político trazidos pelos agenciamentos de discursos por vezes 
complementares, por vezes contraditórios. Assim sendo, as experiências não podem ser compreendidas como conhecimentos lineares, contínuos, acumulativos e acabados, mas analisadas com uma trama rizomática sem começo e sem finitude.

Mesmo que as experiências possuam uma historicidade, também possuem a função de colocar os sujeites para se movimentar no presente, pois elas não são apreendidas para serem reproduzidas (ou transmitidas) e sim para serem vividas. As experiências acontecem na proposta das criações, das migrações, das posições nômades, das potências e negociações para outras vivências e existências.

\section{Referências}

AKOTIRENE, C. O que é interseccionalidade?. Belo Horizonte: Letramento: Justificando, 2018.

ANGEL, T. Manisfesto Freak. FRRRKguys. [S. I.], 6 jan. 2016. Disponível em: http://www.frrrkguys.com.br/manifesto-freak/. Acesso em: 12 dez. 2019.

BRAIDOTTI, R. Sujetos nómades. Buenos Aires: Paidós, 2000.

BUTLER, J. Problemas de gênero: feminismo e subversão da identidade. Tradução Renato Aguiar. Rio de Janeiro: Civilização Brasileira, 2003.

BUTLER, J. Deshacer el genero. Barcelona: Paidos, 2004.

BUTLER, J. Cuerpos que importan: sobre los límites materiales y discusivos del "sexo". 2. ed. Buenos Aires: Paidós, 2008.

DELEUZE, Gilles. "Uma conversa, o que é, para que serve?" In: DELEUZE, Gilles; PARNET, Claire. Diálogos. São Paulo: Escuta, 1998.

DELEUZE, G.; PARNET, C. Diálogos. Tradução Eloisa Araújo Ribeiro. São Paulo: Escuta, 1998.

FOUCAULT, M. A vida dos homens infames. In: FOUCAULT, M. Estratégia, poder-saber. Tradução Vera Lucia Avellar Ribeiro. Rio de Janeiro: Forense Universitária, 2003a. p. 203222. (Ditos e escritos, v. 4).

FOUCAULT, M. Diálogo sobre o poder. In: FOUCAULT, M. Estratégia, poder-saber. Tradução Vera Lucia Avellar Ribeiro. Rio de Janeiro: Forense Universitária, 2003b. p. 253-266. (Ditos e escritos, v. 4).

FOUCAULT, M. Poder-Corpo. In: FOUCAULT, M. Microfísica do poder. Tradução Roberto Machado. 18. ed. Rio de Janeiro: Graal, 2003c. cap. 9, p. 145-152. 
FOUCAULT, M. História da sexualidade 1: a vontade de saber. Tradução Maria Thereza da Costa Albuquerque e J. A. Guilhon Albuquerque. 16. ed. Rio de Janeiro: Graal, 2005.

FOUCAULT, M. A ordem do discurso. 14. ed. São Paulo: Ed. Loyola, 2006.

HALL, S. Quem precisa da identidade?. In: SILVA, T. T. (org.). Identidade e diferença: a perspectiva dos estudos culturais. 2. ed. Petrópolis: Vozes, 2003. p. 103-133.

LE BRETON, D. Adeus ao corpo: antropologia e sociedade. Tradução Marina Appenzeller. Campinas: Papirus, 2003.

MELLO, A. G. Deficiência, incapacidade e vulnerabilidade: do capacitismo ou a preeminência capacitista e biomédica do Comitê de Ética em Pesquisa da UFSC. Ciências e Saúde Coletiva, Rio de Janeiro, v. 21, n.10, p. 3265-3276, 2016.

MELLO, A. G.; NUERNBERG, A. H. Gênero e deficiência: interseções e perspectivas. Revista Estudos Feministas, Florianópolis, v. 20, n. 3, p. 635-655, dez. 2012. Disponível em: http://www.scielo.br/scielo.php?script=sci_arttext\&pid=S0104026X2012000300003 \&lng=en\&nrm=iso. Acesso em: 12 dez. 2019.

NASCIMENTO, M. A. N. Corpos (con)sentidos: cartografando processos de subjetivação de produto(re)s de corporalidades singulares. 2015. 265f. Tese (Doutorado em Psicologia). Faculdade de Ciências e Letras, Universidade Estadual Paulista, Assis, 2015.

NOGUEIRA, C. Interseccionalidade e psicologia feminista. Salvador: Devires, 2017.

SCOTT, J. W. Experiência. In: SILVA, A. L.; LAGO, M. C. S.; RAMOS, T. R. O. (org.). Falas de gênero: teorias, análises, leituras. Florianópolis: Mulheres, 1999. p. 21-55.

SPIVAK, G. C. Pode o subalterno falar?. Tradução Sandra R. G. Almeida, Marcos P. Feitosa e André P. Feitosa. Belo Horizonte: UFMG, 2012.

TEDESCO, S. H.; SADE, C.; CALIMAN, L. V. A entrevista na pesquisa cartográfica: a experiência do dizer. Fractal: Revista de Psicologia, [S. I.], v. 25, n. 2, p. 299-322, aug. 2013. Disponível em: http://periodicos.uff.br/fractal/article/view/4944. Acesso em: 1 fev. 2020.

Recebido em: 31 jul. 2020 Aceite em: 17 set. 2020 